\title{
Prevalence of Helicobacter spp. in Canine Uremic Gastropathy
}

\author{
K.K. Ponnu Swamy ${ }^{*}$, S. Prathaban ${ }^{2}$, C. Balachandran', \\ B. Muralimanohar ${ }^{4}$ and P. Dhanapalan ${ }^{5}$ \\ ${ }^{1}$ Department of Clinics, VC\&RI, Namakkal - 1, Tamil Nadu, India \\ ${ }^{2}$ Department of Clinics, MVC, Chennai - 7, Tamil Nadu, India \\ ${ }^{3}$ Tamil Nadu Veterinary and Animal Sciences University, Chennai - 51, Tamil Nadu, India \\ ${ }^{4}$ Madras Veterinary College, Chennai-07, Tamil Nadu, India \\ ${ }^{5}$ Bioinformatics Center, Madras Veterinary College, Chennai-51, Tamil Nadu, India \\ *Corresponding author
}

\begin{tabular}{|c|c|}
\hline & $A B S T R A C T$ \\
\hline Keywords & \multirow{4}{*}{$\begin{array}{l}\text { The purpose of this study is to assess the prevalence of Helicobacter spp. in stomach of dogs } \\
\text { with renal failure and to document the histopathological changes in Helicobacter spp. } \\
\text { associated uremic gastritis in dogs. The present study consisted of } 10 \text { apparently healthy dogs } \\
\text { and } 35 \text { dogs with chronic renal failure identified by detailed clinical examination, hematology, } \\
\text { serum biochemistry, urinalysis and nephrosonography. Gastroscopy aided mucosal biopsies } \\
\text { were taken using gastrofibrescope (OLYMPUS type GF*) in apparently healthy dogs and dogs } \\
\text { with various grades of Azotenia. The biopsy samples were subjected to Rapid Urease testing, } \\
\text { Culturing of Helicobacter spp., Routine histopathology and Histopathology with special } \\
\text { staining for Helicobacter spp.Cases showing positive results in at least two identification } \\
\text { procedures among the three followed in this were considered as positive fir Helicobacter } \\
\text { spp.Mucosal hyperplasia, increased goblet cell activity, sub-mucosal hemorrhage, atrophy of } \\
\text { gastric glands, severe fibrosis and ulceration with mononuclear cell infiltration were the } \\
\text { histopathological findings in Helicobacter spp. associated uremic gastritis in dogs. }\end{array}$} \\
\hline Article Info & \\
\hline $\begin{array}{l}\text { Accepted: } \\
\text { 24 September } 2018 \\
\text { Available Online: } \\
10 \text { October } 2018\end{array}$ & \\
\hline & \\
\hline
\end{tabular}

\section{Introductions}

Helicobacter spp. are gram negative, microaerophilic, curved to spiral shaped bacteria (Fox. 1998). These organisms are catalase and urease positive (Jalava et al., 1997). Helicobacter pylori has been linked to peptic ulcer disease, gastritis, gastric adenocarcinoma and gastric mucosa associated lymphoma in human patients (Strauss-Ayali and Simpson, 1999). Helicobacter pylori was isolated in human patients with chronic renal failure (Shousha et al., 1989 and Chhinna et al., 1998).
The purpose of this study is to assess the prevalence of Helicobacter spp. in stomach of dogs with renal failure and to document the histopathological changes in Helicobacter spp. associated uremic gastritis in dogs.

\section{Materials and Methods}

\section{Experimental design}

The present study consisted of 10 apparently healthy dogs and 35 dogs with chronic renal failure identified by detailed clinical 
examination, hematology, serum biochemistry, urinalysis and nephrosonography. The dogs with chronic renal failure were then grouped based on degree of azotemia as follows (Mitch. 1991).

Group - I (Mild azotemia, BUN $\leq 50 \mathrm{mg} / \mathrm{dl}, \mathrm{n}$ = 6) Group - II (Moderate azotemia, BUN = $50-90 \mathrm{mg} / \mathrm{dl}, \mathrm{n}=8$ )

Group - III (Severe azotemia, BUN $=90-140$ $\mathrm{mg} / \mathrm{dl}, \mathrm{n}=8)$

Group - IV (Very severe azotemia, BUN $\geq$ $140 \mathrm{mg} / \mathrm{dl}, \mathrm{n}=13$ )

\section{Gastroscopy aided mucosal biopsy}

Gastroscopy aided mucosal biopsies were taken using gastrofibrescope (OLYMPUS type $\mathrm{GF}^{*}$ ) in apparently healthy dogs and clinical cases following standard procedures (Tams, 1990). Four gastric antral biopsy samples were obtained for routine histopathology, rapid urease testing, culture of Helicobacter spp. and special staining for identification of Helicobacter spp. by histopathology.

\section{Routine histopathology}

Gastric antral biopsy samples for histopathology were fixed in $10 \%$ neutral buffered formalin immediately after collection. The fixed specimen was then embedded in paraffin wax, cut into pieces of 3 - $4 \mu$.m. thickness and stained with hematoxylin and eosin as described by Luna (1968). Histopathological changes were recorded.

\section{Rapid urease testing (RUT)}

The biopsy samples for RUT were placed in a test reagent containing $10 \%$ unbuffered urea in distilled water and $1 \%$ phenol red. The sample was then incubated at room temperature. Color change of the test reagent from yellow to pink was taken as positive (Happonen et al., 1998).

\section{Culture and isolation of Helicobacter spp.}

The biopsy samples for Culture and Isolation of Helicobacter spp. were transported in brain - heart infusion broth. The specimen were then cultured in brucella agar enriched with brucella selective supplement and $10 \%$ horse blood containing selected antibiotics (trimethoprim - $2.5 \mathrm{mg} / \mathrm{dl}$; vancomycin - 5 $\mu \mathrm{g} / \mathrm{dl}$ and polymixin-B $-1.25 \mu \mathrm{g} / \mathrm{dl}$ ).

Plates were then incubated at $37{ }^{\circ} \mathrm{C}$, microaerobically with $5 \% \mathrm{O} 2,10 \% \mathrm{CO} 2$ and $85 \%$ N2 for 10 days (Fox. 1998). Growth was visible as thin film 3 to 10 days after incubation. Preliminary identification of Helicobacter spp. was made by morphological characteristics of gram stained smears.

\section{Special staining for identification of Helicobacter spp.}

Gastric biopsy samples for identification of Helicobacter spp. were fixed in $10 \%$ neutral buffered formalin immediately after collection.

The fixed specimen was then embedded in paraffin wax, cut into pieces of $3-4 \mu$.m. thickness and stained with Toulidine blue in Sorensons' phosphate buffer (Stevens and Francis. 1996).

\section{Results and Discussion}

The results of rapid urease testing, culture and histopathology are summarized in Table 1.

\section{Rapid urease testing (RUT)}

3 dogs in control group, 1 dog in group-1, 4 dogs in group-2, 3 dogs in group-3 and 8 dogs in group-4 were positive in rapid urease testing (Plate-1). 
False positive and false negative results are common in rapid urease testing. Negative result may occur when the number of bacteria is lesser in the sample, it has been calculated that $10^{4}$ organisms are required for a positive result (Bourguignon. 1989).

Similarly other urease-producing bacteria like Proteus mirabilis can give false positive results.

\section{Culture of Helicobacter spp.}

Helicobacter spp. were cultured and identified in 1 dog from group-3 and 3 dogs from group4 (Plate-2). Among 3 positive dogs in group-4, Helicobacter spp. was not identified in $1 \mathrm{dog}$ by histopathology. The definitive diagnosis of Helicobacter spp. requires culture and isolation (Fox. 1998).

Table.1 Helicobacter spp. isolation and identification

\begin{tabular}{|c|c|c|c|c|}
\hline S. No & Groups & RUT & Culture & Histopathology \\
\hline 1 & Control $(\mathrm{n}=10)$ & 3 & --- & --- \\
\hline 2 & I $(\mathrm{n}=6)$ & 1 & --- & --- \\
\hline 3 & II $(\mathrm{n}=8)$ & 4 & --- & --- \\
\hline 4 & III $(\mathrm{n}=8)$ & 3 & 1 & 1 \\
\hline 5 & IV $(\mathrm{n}=13)$ & 8 & $3(1)^{*}$ & $3(1)^{*}$ \\
\hline
\end{tabular}

* Out of 3 positive culture results one was negative in histopathology

** Out of 3 positive histopathology results one was negative in culture

Plate.1 Rapid urease testing

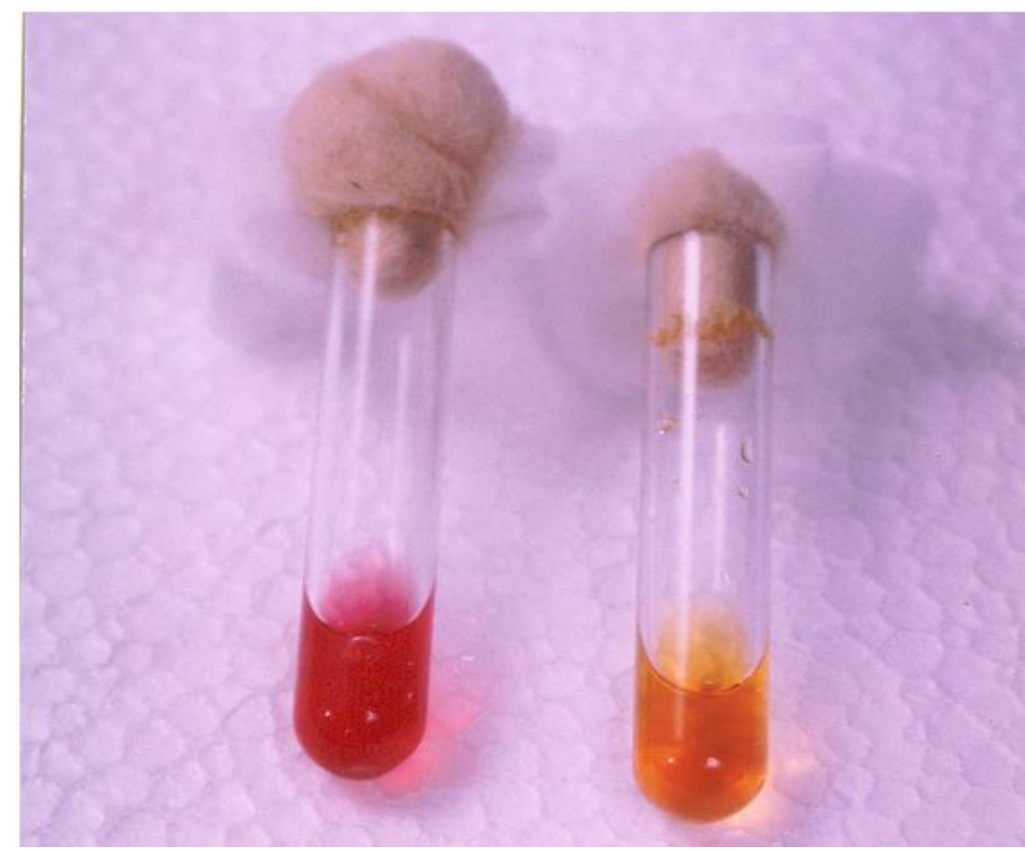


Plate.2 Helicobacter spp Gram's stain (100X)

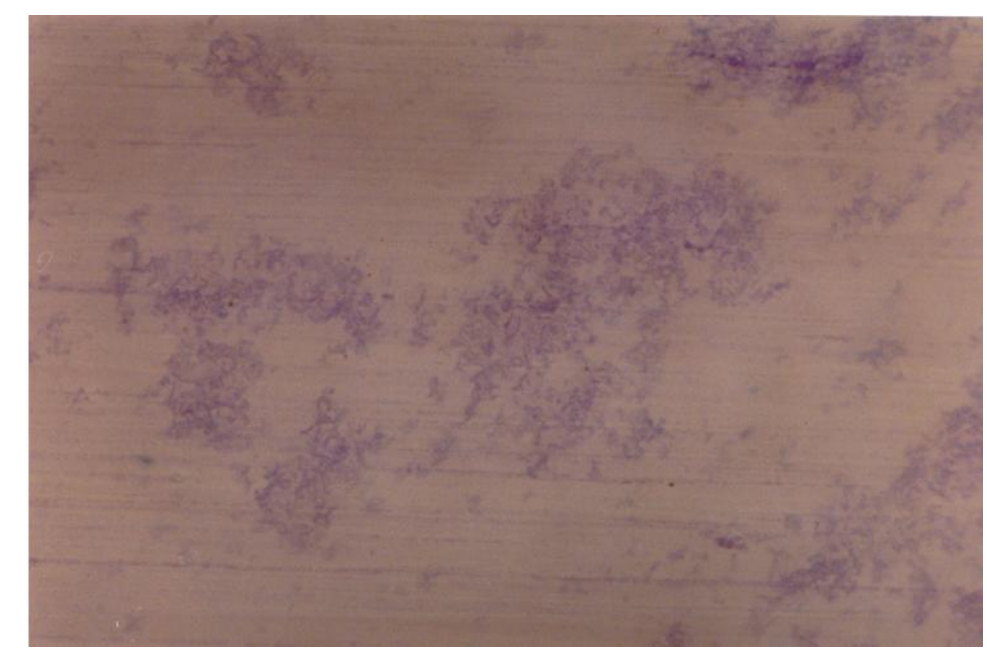

Plate.3 Helicobacter spp in gastric biopsy (Toulidine blue in Sorenson's phosphate buffer, 100X)

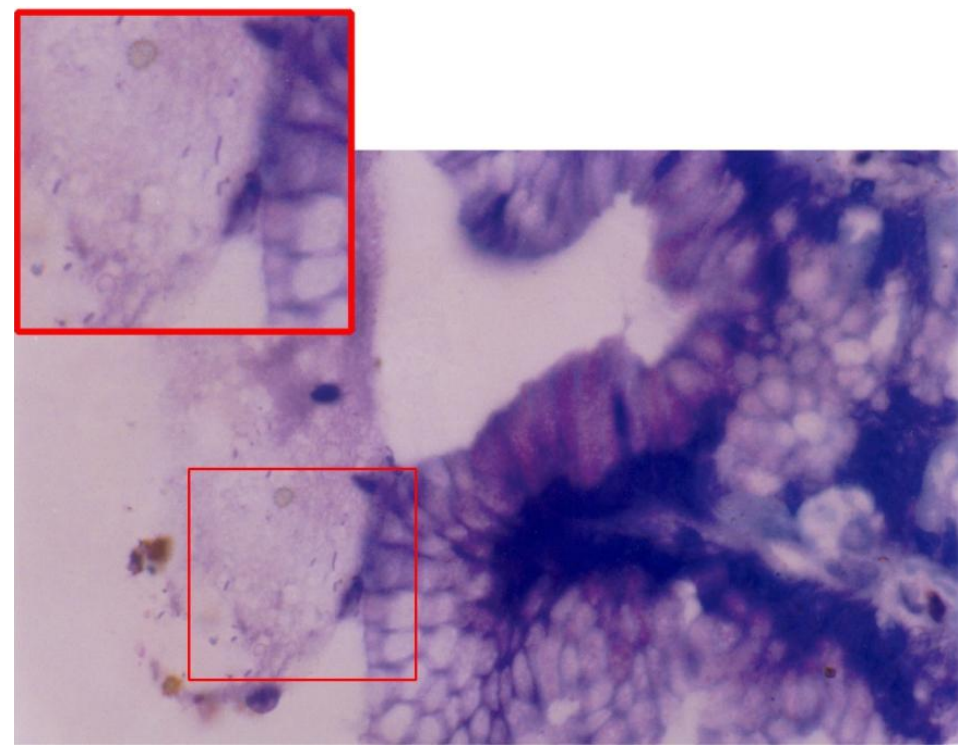

Detection of Helicobacter spp. by Strauss-Ayali and Simpson (1999) and the histopathology detection of dark blue Helicobacter spp. closely associated with gastric epithelium

The bacteria were practically unidentifiable concurred with Stevens and Francis (1992). by H\&E staining. However, Helicobacter spp. were identified as blue curved to spiral organisms against variable blue background in $1 \mathrm{dog}$ in group-3 and 3 dogs in group-4 (Plate-3). Among 3 positive dogs in group-4, the organisms failed to grow in 1 dog during culturing. The difficulty in identifying the organisms by $\mathrm{H} \& \mathrm{E}$ staining concurred with

\section{Histopathological changes}

The histopathological changes in gastric biopsy samples stained with $\mathrm{H} \& \mathrm{E}$ Helicobacter spp. associated gastritis were mucosal hyperplasia, increased goblet cell activity, sub-mucosal hemorrhage, atrophy of 
gastric glands, severe fibrosis and ulceration with mononuclear cell infiltration (StraussAyali and Simpson, 1999).

Cases showing positive results in at least two identification procedures among the three followed in this were considered as positive fir Helicobacter spp. In this regard only 5 dogs out of 35 clinical cases $(14.28 \%)$ with chronic renal failure were positive for Helicobacter spp. These 5 dogs belong to group-3 and group-4. Hence, it is concluded that the prevalence of Helicobacter spp. was related to the severity of azotemia. Mucosal hyperplasia, increased goblet cell activity, sub-mucosal hemorrhage, atrophy of gastric glands, severe fibrosis and ulceration with mononuclear cell infiltration were the histopathological findings in Helicobacter spp. associated uremic gastritis in dogs.

\section{References}

Bourguignon, G., J. Croze, Riard. P, Hostein. $\mathrm{J}$ and Leploc. P. 1989. In vitro study of different media to detect urease of Camphylobacter pylori. In: Gastroduodenal pathology and Camphylobacter pylori, (eds) F, Megraud and H, Lamoulialtte, Elsevier, Amsterdam. Pp. 57-62.

Chhina, R.S., Chhina. D, Ram. S, Midha. V, Khaira N.S. and Khurana. S. 1998. Helicobacter pylori- prevalence in chronic renal failure. Indian J. Nephrol. 8(3): 98-100.

Fox, J.G. 1998. Gastric Helicobacters. In: Infectious diseases of dog and cat, 2nd Edn, (edr) C.E, Greene, W.B. Saunders Co, Philadelphia, Pp. 229-233.
Happonen, I., Linden. J, Saari. S, Karjalaineen. M, Hanninen. M.L, Jalava. K and Westermarck E. 1998. Detection and effects of Helicobacters in healthy dogs and dogs with signs of gastritis. J.Am.Vet. Med.Assoc., 213(12):1767-1774.

Jalava, K., Kaartinen. $\mathrm{M}$ and Utriainen. M. 1997. Helicobacter salomonis sp, a noval canine gastric Helicobacter spp related to Helicobacter felis and Helicobacter bizzozeroni. Inf. I. Syst. Bacteriol., 47: 975.

Luna, L.G. 1968. Manual of Histological staining methods. Armed forces institute of pathology. The Blackinstan Division, McGraw Hill book co Inc, New York.

Mitch, W.E.1991. Dietary protein restriction in patients with chronic renal failure. Kidney.Int., 40:326.

Shousha, S., Keen C and Parkins R.A. 1989. Gastric metaplasia and Camphylobacter pylori infection of duodenum in patients with chronic renal failure. J. Clin. Pathol. 42: 348-351.

Stevens, A and Francis R.F. 1996. Microorganisms. In: Theory and Practice of Histological techniques. (edr) Bancroft. Pp. 298.

Strauss- Ayali, D. and Simpson. K.W. 1999. Gastric Helicobacter infection in dogs. Vet. Clinics. N. Am. Small. Anim. Pract., 29(2): 397-414.

Tams, T.r. 1990. Small animal endoscopy, C.V. Mosby Company, St. Louis. Pp. 43-45, 90-91.

\section{How to cite this article:}

Ponnu Swamy, K.K., S. Prathaban, C. Balachandran, B. Muralimanohar and Dhanapalan, P. 2018. Prevalence of Helicobacter spp. in Canine Uremic Gastropathy. Int.J.Curr.Microbiol.App.Sci. 7(10): 3198-3202. doi: https://doi.org/10.20546/ijcmas.2018.710.370 